physicians needed exceeds the number of accepted medical students.

During the academic year 1975-76 there was a considerable rise of political activity among students. They raised their voices in protest against the changes in the constitution. More recently they protested against the expulsion of their colleague $\mathbf{M r}$ Jacek Smykala from the Medical Academy in Szczecin (during a tutorial class in economics he asked what part of the national budget is allocated to the police force), and against the imprisonment of their colleague Mr Stanislaw Kruszynski from the Catholic University in Lublin (the only private university in Poland), who was sentenced to six months in prison for writing unfavourable opinions about the social system in Poland in private letters to his relatives and friends. From Warsaw University alone about 800 people signed this protest.

At the beginning of 1976 a reduction of staff (up to 10\%) took place in many research institutes, including those connected directly with industry. These reductions touched universities and industries of PAS to a lesser extent but it was decided to freeze the number of their staff for the next three years.

The Polish economy, as is commonly accepted, is now entering a very difficult period. One of the signs of this was the government's proposals to increase the food prices in June (meat by about $70 \%$, sugar $100 \%$ and so on) which would have caused a fall in the spend- ing power of wages by about 20 to $30 \%$. The wave of strikes ( 70 to $80 \%$ of big factories according to unofficial figures) and unrest in a few places forced the government to rescind this proposal. Science seems to be near the top of the list for economies. According to some sources it has already been decided to halve the rate of investment in science. Considerable political tension in the whole country has not by-passed the scientists. Speculations about personal changes have wide circulation. Meanwhile the repressions against those involved in strikes and protests have already begun.

As in all countries of the communist block, scientists in Poland have no real representation to defend their own interests and those of science. The Polish Academy of Sciences is the agent of the government and provides no more than formal representation. For example, recently, in June 1976, after the abortive attempt to increase prices, the Praesidium of PAS at its meeting in the metallurgical factory in Silesia wrote a letter of adulation to $\mathrm{Mr}$ Gierek, the Secretary of the Party. A few months previously, his son, Professor Adam Gierek, was elected to the PAS; perhaps those who voted in his favour had in mind the dire fate of the Romanian Academy, which, as it is said, was a consequence of its refusal to elect Mrs Ceaucescu (wife of the Secretary of the Party in Romania) to the Academy.

These and similar steps do not con-

\section{Sorry, for copyright reasons some images on this page may not be available online}

\section{Polish leader Edward Gierek}

tribute to the authority of PAS and do not reflect the views of the Polish scientific community. An interesting new development in this community and in the whole group of intellectuals is the collaboration of differently minded people, rightists and leftists, catholics and even members of the party. This collaboration is an outcome of the common feeling that the present policy endangers not only the further development of science, but also the very existence of independent Poland, and that the most important task confronting the intelligentsia is the defence of the national identity.

\title{
Artificial intelligence in education
}

\section{Miranda Robertson discusses research aimed at exploiting computers in human communication and teaching}

IF the principal goal of research in artificial intelligence (AI) has been the development of intelligent machines, an increasingly conspicuous sideline is the promotion of intelligence in human beings. This social orientation has been stimulated partly by Newell and Simon at Carnegie Mellon, and the ideas of Papert and Minsky, at the Massachusetts Institute of Technology, (MIT), who see in artificial intelligence a new way of looking at the nature and development of ratural intelligence.

Papert has for some years been an advocate of the use of sophisticated computer programming languages to help children learn how to think. Writing a program in a high-level language involves the expression of thought processes which would not usually be formulated. When there is a mistake ("bug") in the program, the child can retrace his thoughts in the program and understand his own mistake. The result, Papert believes, is to increase the child's intellectual effectiveness in general and make him more articulate.

\section{LOGO learning for children}

That is the idea behind experiments which have been going on in the LOGO laboratory at MIT for about three years. LOGO is a high level language which children can use to program various devices, the best known of which is a mechanical "turtle" with a retractable pen.

Usually, the child begins by learning how to draw geometric designs by programming the turtle; later, as the system becomes more familiar, the turtle can be replaced by a somewhat nimbler oscilloscope trace. One important advantage of a LOGO system over more conventional curricula is that children enjoy working with it and it can be used to overcome the resistance that many children develop to learning mathematics.

So far, the experiments at MIT have not been sufficiently systematic to produce clear evidence for Papert's persuasive arguments. Up to now, the children have been drawn largely from the families of MIT research workers and from a local school, neither (probably) very representative; and the classes have been supervised by research staff, in particular Dr Jeanne Bamberger, rather than by professional teachers.

There has for some time been talk of an entire school geared to the LOGO system, and where about half the school curriculum would be undertaken at a computer terminal. But this ambitious project is not expected to start in earnest for another two years, during which a small group of teachers will be trained in LOGO, a pilot LOGO educational project will be run with the cooperation of one of the Cambridge or Boston schools, and some thought will be given to how the children's intellectual development should be evaluated. 
Evaluation presents a special problem because it is not clear that the intellectual abilities LOGO is supposed to foster would necessarily be revealed by conventional psychometric tests. Papert and his colleague Marvin Minsky, who specialises in theories of intelligence, maintain not only that conventional tests are inappropriate, but that the qualitative difference they would expect to see in the children would be great enough to make statistical tests unnecessary. On the other hand they do not expect to be able to show those differences with anything short of a total "LOGO environment" and that is two or three years off.

In the meantime, however, their ideas have inspired a number of schools and universities elsewhere to set up their own experiments with LOGO or other similar systems. Of those, a small research project and the Artificial Intelligence Department at the University of Edinburgh is the furthest advanced with a scheme for providing more rigorous experimental evidence. Jim Howe, Tim O'Shea and Ben du Boulay have enlisted the cooperation both of a local school and of a teacher training college with the aim of finding out how learning may not only help pupils to learn, but teachers to teach. Eleven-year-old children from George Herriots, a direct grant Edinburgh boys' school, have now been taking part for a year in LOGO classes in the course of which a LOGO curriculum has been designed, and practical experience has led to various improvements both in the language itself and to the development of new devices.

\section{Children with problems}

Although the Edinburgh group do not entirely share Minsky's and Papert's contempt for all psychological testing (indeed part of the research project is to design suitable tests), the

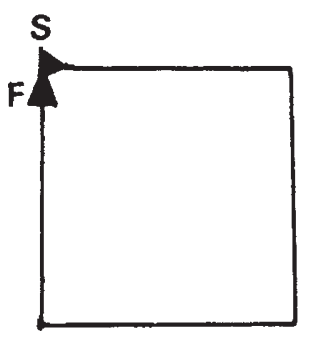

w: TO SQUARE d:1 FORWARD 100 d:2 RIGHT 90 d:3 FORWARD 100 d:4 RIGHT 90 d:5 FORWARD 100 d:6 RIGHT 90 d:7 FORWARD 100 square defined w: SQUARE

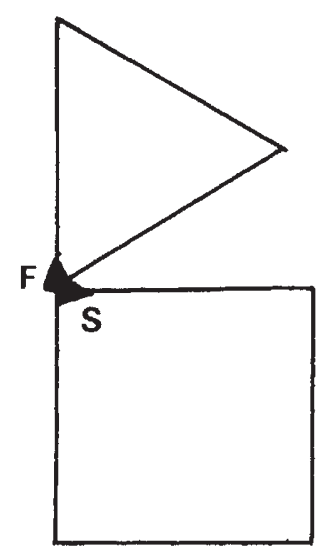

w: TO HOUSE d:1 SQUARE $\mathrm{d}: 2$ TRIANGLE END house defined w: HOUSE

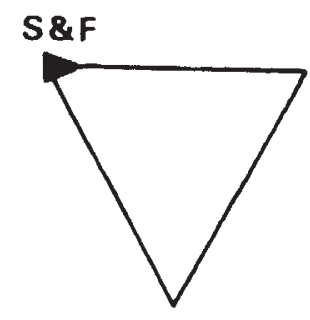
w: TO TRIANGLE
d: 1 FORWARD 100
d:2 RIGHT 120
d:3 FORWARD 100
d:4 RIGHT 120
d:5 FORWARD 100
d:6 RIGHT 120
d: END
triangle defined
w: TRIANGLE

This is an example of a "bug" which ing learned to write procedures to draw a square and a triangle, the child puts the two programs together to make a "house". In this particular case, the bug arises because the turtle's change in orientation (indicated by arrows: $S=$ starting position, $F=$ finishing position) in the course of drawing the two shapes has not been correctly predicted. w: prompt typed when the computer is ready to take a command; $d$ : prompt typed when computer is in the definition mode. is commonly encountered when, hav- most striking effects they have seen so far have been precisely of a kind that psychometric tests would miss. Some of the most interesting evidence so far is anecdotal, and the example of one particular child with a problem suggests that a particular advantage of LOGO learning may be in bridging the communications gap between teacher and pupil, especially where for one reason or another that is particularly difficult.

The anecdotal evidence concerns a "dyslexic" boy who was included by chance in the first group of 18 children to be taught LOGO. In spite of remedial lessons from sympathetic and enthusiastic specialists for two years, neither his reading and writing nor his classroom performance had improved, and he was well established in the role of class clown and dunce. LOGO programming, unlike the rest of his school work, however, came relatively easily to him and he rapidly reached a point where he was able to teach other boys. That brought about a change in his classmates' attitude to him and a conspicuous increase in his own selfconfidence. O'Shea illustrates the point with an account of an argument between the boy and his teacher during a classroom lesson on sets. Asked to name the set of even numbers divisible by two and the set of odd numbers divisible by two, he responded with, "the set that never finishes and the set that never starts". The textbook answers are the infinite set and the empty set, and the teacher marked him wrong.

In a way that would have been uncharacteristic before he started learning LOGO, the boy argued with his teacher and as a result was awarded half marks. Part of the significance of that story, for Howe and O'Shea, lies in the phrasing of the boy's "wrong" response, which, like the definition of a LOGO program, is expressed in terms of procedures. The implication is that learning LOGO supplied not only the confidence to argue, but the language in which to do so (incidentally, a school inspector spontaneously remarked of other boys in the group that they were exceptionally mathematically argumentative).

\section{LOGO learning for teachers}

One of Papert's most important claims has been that learning LOGO provides a descriptive system within which to think and communicate; and this is relevant not only to the private intellectual development of individual children, but to the interaction between pupil and teacher: it can also help the teacher to understand and express what he has to teach. Papert maintains that what makes so many common skills (such as riding a bicycle) so hard 
to teach is the lack of an adequate way of describing them. Because learning with LOGO is learning within a descriptive system, it makes everything explicit and thus automatically more communicable.

That is the rationale for an experimental LOGO course which Ben du Boulay has been running at a local college for trainee primary school teachers. Primary school mathematics teaching is often a special problem partly because the teachers' own grip on the subject is none too firm. The aim of du Boulay's part of the Edinburgh project is to see whether LOGO learning has a function in helping primary teachers both to understand and to explain mathematics. That research is still at a preliminary stage.

But LOGO learning as a "catalyst" to communication is an important theme of the Edinburgh research. The particular term catalyst has been adopted by Sylvia Weir to describe the effect of LOGO learning on communications between an autistic child and the normal adults who work with him. Weir, working with Ricky Emmanuel, has found that allowing an autistic child to control the turtle from an array of buttons on a box stimulated him to communicate with them in a spontaneous way they had rarely seen in any other context.

She attributes this "humanising" effect to what she calls "shared relevance": the transparent connections between the pressing of the buttons and the movements of the turtle, and between the turtle's actions and the child's own movements in space provide, in her view, a basis of shared relevance, or a common framework, within which the child and the adults can communicate. Building on a framework of shared knowledge is the basis for any intelligent and effective teaching, and educationists acknowledge that good teaching must depend on the teacher's being able to reach out to the child's position and lead him from there. LOGO learning may be a special help where the subnormality of the child makes the gap unusually large and the teacher's task unusually difficult.

\section{Future of LOGO}

But the commitment of the Edinburgh group is to find hard evidence for the possible benefits of computerbased teaching systems like LOGO. Most of the known methods of educational assessment will be used for that purpose, and Howe and O'Shea have added one new test specially designed to reflect some of the skills that LOGO is supposed to promote. O'Shea calls it the "articulation test", and it tests the ability of a child sitting on one side of an opaque screen to instruct his partner on the other side on how to construct a particular pattern from coloured blocks. That apparently simple problem has been known to reduce an untutored child to tears of inarticulate frustration, so the results should be interesting; but so far, they are only suggestive.
On what evidence there already is, what part are computer-based systems really likely to play in future education? Papert purports to believe that the future of education and computerbased systems are one and the same, and the next few decades will see the day when each child sits at home at his own computer terminal, without going to school at all. Expense he shrugs off on the grounds that electronics, unlike anything else, are getting exponentially cheaper (consider the cost of the pocket calculator five years ago and now). Nonetheless, equipment of any kind is expensive and computers and their peripherals will remain more expensive than books. And although the Edinburgh research team has been impressed by the way that Papert's educational insights have been borne out, from the practical point of view their attitude is both more conservative and more pragmatic than his.

First, they do not see in LOGO a means of disposing of the teacher: the idea is that such systems may make conventional teaching methods more effective, not that they should replace them. Second, experience is beginning to suggest that the most effective use of computer systems may turn out to be in the education of subnormal children or those with other special problems. If the Edinburgh group can be accused of having a vision, then it is of machines which foster human interactions, rather than making them obsolete.

\section{BRITAIN}

\section{Benn spells it out}

Developments on the British energy

front are fast and furious, with nuclear power capturing most attention. Chris Sherwell reports.

FAST moving sectors of the British economy are not in great abundance these days, but there is one that is beginning to behave in a manner representative of a seething hive of activity. Hardly surprising, for it is none other than the energy sector itself. And not a little of this is due to the increasingly voluble debate over nuclear power.

The arguments over whether Britain should have nuclear power already having been settled, the manner in which it is to be deployed and utilised is now at issue. That includes the question of timing, so there are tactical as well as strategic policy decisions to be taken. The latest involves the Steam Generating Heavy
Water Reactor (SGHWR), expenditure on which was deferred for a year in the latest round of government spending cuts.

The cut means a saving for 1977-78 of $£ 40$ million, and a reduction of $£ 5$ million on research for the project. That in turn has made the broadening debate on the future of the SGHWR either more pointless or more controversial, depending on your perspective. But it hasn't prevented a start to the hearings of the House of Commons Select Committee on Science and Technology on the subject. They began this week, Mr Anthony Wedgwood Benn, Secretary of State for Energy, answering questions.

Mr Benn was fresh from his discussions at the end of last week with Sir Arthur Hawkins, chairman of the Central Electricity Generating Board (CEGB), who supported the pressurised water reactor when a choice was being made in Britain in 1974 but has since, on $\mathrm{Mr}$ Benn's testimony, given every assistance regarding the SGHWR. Sir Arthur was, however, expected to deploy cost estimates and electricity demand forecasts to advise against an immediate go-ahead, on the SGHWR or anything else. $\mathrm{Mr}$ Benn also had before him a report submitted within the past week from Sir John Hill, chairman of the UK Atomic Energy Authority (UKAEA), assessing the progress made so far on the SGHWR.

It was soon apparent that $\mathrm{Mr}$ Benn was concerned to make only four main points. One, as he pointed out at the beginning, the middle and the end of his evidence, the British Government has not yet reached a decision to cancel the SGHWR, nor even a preliminary view on the matter. Two, the decision through spending cuts to postpone for a year its commissioning, while possibly having consequences for the nuclear industry outside the SGHWR programme, was the product of deferment presenting itself as an option. This was in turn a result of "natural slippage" on the SGHWR's reference design and safety standards working in the same direction as the effect of 